\title{
Big Data Analytics and Intelligence: A Perspective for Health Care
}

\author{
Muruganantham A., Phong Thanh Nguyen, E. Laxmi Lydia, K. Shankar, Wahidah Hashim, \\ Andino Maseleno
}

\begin{abstract}
The term big data refers to a group of large and vast amount of data collected from many research organizations, hospitals and scientific organizations which can be available for the healthcare. Such big data have potential for improving in the research in healthcare. The big data helps to analyze the clinical datasets and provides the key insights for the patients care. Such data can be analyzed by several multidisciplinary methods. The big data and intelligence model also helps to provide support in taking recommend action and make the decision making model more strong. The Healthcare medical artificial intelligence system mainly uses a computer software to perform the health and clinical diagnoses and suggest the proper treatments. Predictive analysis is also the most important part of Big Data Analytics which use datasets and historical data to make the predictions about the disease. But such predictions results may vary for person to person. Every person have different immunity power, so an detailed research may help to lead better results. There are many techniques and algorithms are available such as PPDM, Machine Learning, Data Mining Algorithms, Artificial Intelligence etc. In this research it is studied that how health care data can helps patients in predicting diseases and improve the treatment

Keywords: Big Data Analysis for Health Care, Data Mining, Artificial Intelligence, Privacy Preserving Data Mining.
\end{abstract}

\section{INTRODUCTION}

The big data analytics is the process to get vast data from the research organizations in a encrypted pattern [1-3]. Then examine, correlate the data and compare it with the previously submitted data [4-6]. Once data is analyzed then produce the insights and a strong decision support system [7-9]. Such system helps to take faster decision to support healthcare in a better way. The enormous information breaks down the clinical datasets and gives the key bits of knowledge to the patients care. Such information can be broke down by a few multidisciplinary strategies.

Revised Manuscript Received on July 22, 2019.

Muruganantham A., Department of Computer Science, Kristu Jayanti College, India.

Phong Thanh Nguyen, Department of Project Management, Ho Chi Minh City Open University, Vietnam.

E. Laxmi Lydia, Vignan's Institute of Information Technology (A), Department of Computer Science and Engineering, Visakhapatnam, Andhra Pradesh, India.

K. Shankar, Department of Computer Applications, Alagappa University, India.

Wahidah Hashim, Institute of Informatics and Computing Energy, Universiti Tenaga Nasional, Malaysia.

Andino Maseleno, Institute of Informatics and Computing Energy, Universiti Tenaga Nasional, Malaysia.

\section{Big Data ANALYTICS AND INTELLIGENCE MODEL}

The enormous information and insight model additionally offers help in making suggest move and settle on the basic leadership model increasingly solid [8-11]. Figure 1 shows the basic model of big-data analytics and intelligence system providing support of better healthcare.

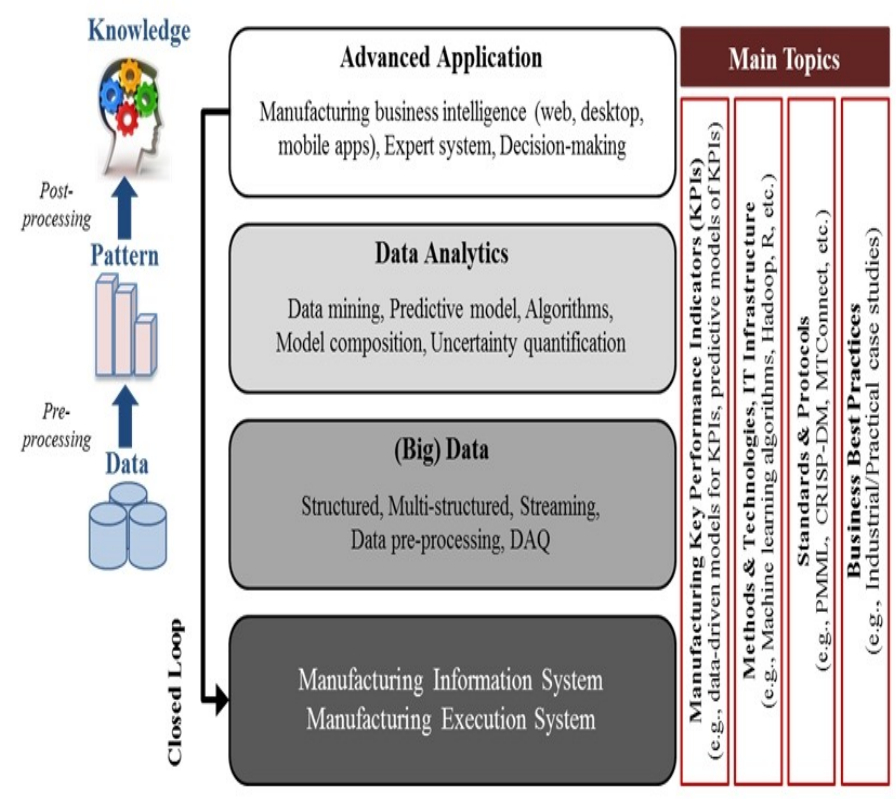

Figure 1. The basic model of Big-Data Analytics and Intelligence System providing support of better healthcare

The Healthcare medicinal man-made consciousness framework essentially utilizes a PC programming to play out the wellbeing and clinical findings and recommend the best possible medications [12-15]. Prescient examination is additionally the most significant piece of Big Data Analytics which use datasets and authentic information to make the expectations about the ailment [16-18]. 
Big Data Analytics and Intelligence: A Perspective for Health Care

New Trends and Applications of Big Data Analytics for Medical Science and Health Care

- Decrease Fraud and Enhance Security

- Electronic Health Records (EHRs)

- Enormous Data to Cure Cancer

- Improving Patient Engagement

- Incorporating Big Data with Medical Imaging

- $\quad$ Ongoing Alerting

- Patients Predictions for an Improved Staffing

- Prescient Analytics in Healthcare

- Telemedicine

- Utilizing Health Data for Informed Strategic Planning

Contextual investigations on the Basis of Different Applications of Big Datathat as it may, such forecasts results may differ for individual to individual. Each individual have distinctive invulnerability control, so a definite research may lead better outcomes. There are numerous methods and calculations are accessible, for example, PPDM, Machine Learning, Data Mining Algorithms, Artificial Intelligence and so on.

- $\quad$ Research Foundations

- Medical Survey
- Hospitals Patient Data

- Digital Image

- Sensors

- Historical Data Sets

- Recycle Datasets

- Private Medical Agencies

- Hospitals Countries Data

In this examination it is considered that how a social insurance information can helps patients in foreseeing maladies and improve the treatment. There are many sources of such data.

\section{BIG DATA ANALYTICS IMPORTANCE}

The Big analytics research and the artificial intelligence may provide high-end solutions to much serious disease. Huge information investigation applications empower huge information examiners, information researchers, prescient modelers, analysts and different examination experts to break down developing volumes of organized exchange information, in addition to different types of information that are frequently left undiscovered by regular business knowledge and examination programs. Figure 2 shows big data analytics key benefits.

\section{Analytics - Key Benefits}

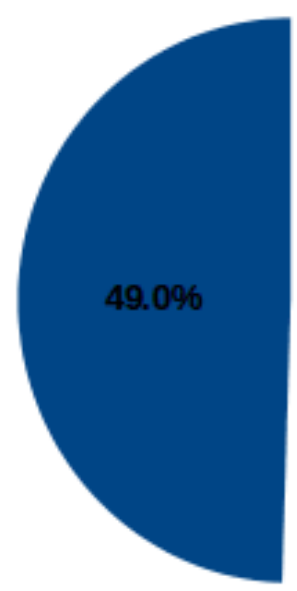

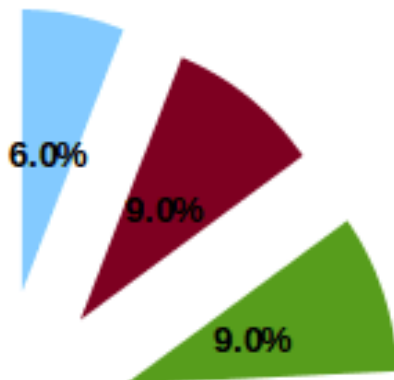

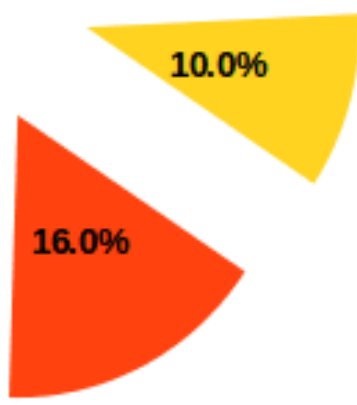

Better Decision-Making

Better Enablement of Key Strategic Initiatives

Better Relationships with Customers

Better Sense of Risk

Better Financial

Performance

Others

\section{Source:'Peer- Research Big Data Analytics Survey}

Figure 2. Big Data Analytics key benefits

The Big data and intelligence system can support in achieve the goals in healthcare. 
Table 1: The use of Big Data and Intelligence in Patient Healthcare

\section{Build sustainable healthcare systems} outcomes
Presently the healthcare is the most important concern for the research industry. The industry is only focusing to reduce the time required to obtain results and at the same time save the cost of required resources. The research organizations and researchers are totally focusing on the way to utilize the available resources in an efficient way.

The healthcare scientific and research organizations focus on the methodology by which the patient involvement and personal care can be improvement. Such strategy helps to handle patient in a efficient way. The interaction with the patient individually is very important and helps to get the research data more easily.

Increase access to healthcare

The population is the major problem for healthcare approach. It is not possible to make every facility everywhere.

That includes anunmanaged information collected from many resources for instance, web survey forms managed by survey agencies, Server Logs, and online medical datasets, data from customer messages and overview reactions, mobile phone records, and software information caught by sensors associated with the web of things.

\section{Medical Image Processing ANd Big DATA}

The Digital imaging gives significant information on life systems and organ work notwithstanding distinguishing diseasesstates. Also, it is used for organ depiction, distinguishing tumors in lungs, spinal disfigurement finding, corridor stenosis identification, aneurysm discovery, and so forth.Figure 3 shows big data medical research and impact.

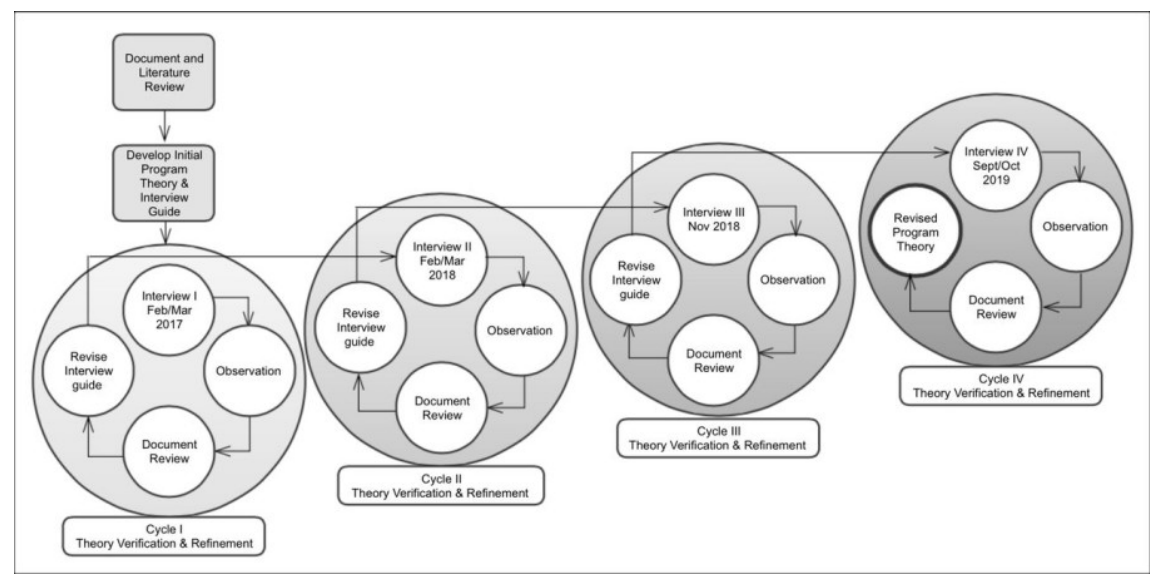

Figure 3. Big Data Medical Research and Impact

In these applications handling strategies, for example, improvement, division and denoising notwithstanding AI techniques are utilized. As the size and dimensionality of information increment, understanding the conditions among the information and planning e-client, exact and computationally effective strategies request new computeraided systems and stages. The fast development in the quantity of health care associations just as the quantity of patients has brought about the more noteworthy utilization of computer aided medicinal diagnostics and choice emotionally supportive networks in clinical settings.
By and by the human services is the most significant worry for the examination business. The business is just centering to lessen the time required to get results and simultaneously spare the expense of required assets. The exploration associations and analysts are thoroughly concentrating while in transit to use the accessible assets in a productive manner. The medicinal services logical and inquire about associations center around the procedure by which the patient inclusion and individual consideration can be improvement. 


\section{Big Data Analytics and Intelligence: A Perspective for Health Care}

Such system handles persistent in a proficient manner. The collaboration with the patient exclusively is significant and gets the exploration information all the more effectively. The populace is the serious issue for medicinal services approach. It is absurd to expect to make each office all over the place.

\section{CONCLUSION}

The huge data and knowledge model moreover offers assistance in making propose move and choose the essential initiative model progressively strong. The Healthcare restorative man-made cognizance system basically uses a PC programming to play out the prosperity and clinical discoveries and suggest the most ideal meds. Insightful assessment is furthermore the most critical bit of Big Data Analytics which use datasets and genuine data to make the assumptions regarding the illness. The enormous information examination is the procedure of get huge information from the exploration associations in a scrambled example. At that point analyze, connect the information and contrast it and the recently submitted information. When information is dissected at that point produce the experiences and a solid choice emotionally supportive network. Such framework takes quicker choice to help social insurance in a superior manner.

The colossal data separates the clinical datasets and gives the key bits of learning to the patients care. Such data can be penniless somewhere around a couple multidisciplinary techniques. The enormous information and insight model likewise offers help in making suggest move and settle on the basic leadership model progressively solid. The Healthcare therapeutic computerized reasoning framework fundamentally utilizes a PC programming to play out the wellbeing and clinical judgments and propose the best possible medicines. Predictive investigation is additionally the most significant piece of Big Data Analytics which use datasets and chronicled information to make the expectations about the ailment. However, such forecasts results may change for individual to individual. Each individual have distinctive invulnerability control, so a point by point research may lead better outcomes. There are numerous systems and calculations are accessible, for example, PPDM, Machine Learning, Data Mining Algorithms, Artificial Intelligence and so forth. In this examination it is considered that how medicinal services information can helps patients in foreseeing illnesses and improve the treatment.

\section{REFERENCES}

1. Huda, M., Maseleno, A., Atmotiyoso, P., Siregar, M., Ahmad, R., Jasmi, K., \& Muhamad, N. (2018). Big data emerging technology: insights into innovative environment for online learning resources. International Journal of Emerging Technologies in Learning (iJET), 13(1), 23-36.

2. Huda, M., Maseleno, A., Shahrill, M., Jasmi, K. A., Mustari, I., \& Basiron, B. (2017). Exploring Adaptive Teaching Competencies in Big Data Era. International Journal of Emerging Technologies in Learning, 12(3).

3. Maseleno, A., Sabani, N., Huda, M., Ahmad, R., Jasmi, K. A., \& Basiron, B. (2018). Demystifying learning analytics in personalised learning. International Journal of Engineering \& Technology, 7(3), 1124-1129

4. Huda, M., Maseleno, A., Teh, K. S. M., Don, A. G., Basiron, B., Jasmi, K. A., ... \& Ahmad, R. (2018). Understanding Modern
Learning Environment (MLE) in Big Data Era. International Journal of Emerging Technologies in Learning, 13(5).

5. Andrew McAfee, Erik Brynjolfsson, Thomas H Davenport, DJ Patil, and Dominic Barton. Huge data:the the executives transformation. Harvard Bus Rev, 90(10):60 68, 2012.

6. Cli ord Lynch. Huge information: How do your information develop? Nature, 455(7209):28 29, 2008.

7. Sugiyarti, E., Jasmi, K. A., Basiron, B., Huda, M., Shankar, K., \& Maseleno, A. (2018). Decision support system of scholarship grantee selection using data mining. International Journal of Pure and Applied Mathematics, 119(15), 2239-2249.

8. Maseleno, A., Hasan, M. M., \& Tuah, N. (2015). Combining Fuzzy Logic and Dempster-Shafer Theory. Indonesian Journal of Electrical Engineering and Computer Science, 16(3), 583-590.

9. Maseleno, A., Huda, M., Siregar, M., Ahmad, R., Hehsan, A., Haron, Z., ... \& Jasmi, K. A. (2017). Combining the previous measure of evidence to educational entrance examination. Journal of Artificial Intelligence, 10(3), 85-90.

10. Adam Jacobs. The pathologies of huge information. Correspondences of the ACM, 52(8):36 44, 2009.

11. Paul Zikopoulos, Chris Eaton, et al. Seeing huge information: Analytics for big business class hadoop and spilling information. McGraw-Hill Osborne Media, 2011.

12. James Manyika, Michael Chui, Brad Brown, et al. Enormous information: The following wilderness for development, rivalry, and profitability. 2011.

13. Je rey J Borckardt, Michael R Nash, Martin D Murphy, Mark Moore, Darlene Shaw, and Patrick O'Neil. Clinical practice as characteristic lab for psychotherapy look into: a manual for case-based timearrangement examination. American analyst, 63(2):77, 2008.

14. Leo Anthony Celi, Roger G Mark, David J Stone, and Robert A Montgomery. Enormous information in the emergency unit. Shutting the information circle. American diary of respiratory and basic consideration drug, 187(11):1157, 2013.

15. Marie-Helene Teiten, Serge Eifes, Simone Reuter, Annelyse Duvoix, Mario Dicato, and Marc Diederich. Gene expression proling related to anti-inammatory properties of curcumin in k562 leukemia cells Annals of the New York Academy of Sciences, 1171(1):391398, 2009.

16. Katherine C Chen, Laurence Calzone, Attila Csikasz-Nagy, et al. Integrative analysis of cell cycle control in budding yeast. Molecular biology of the cell, 15(8):38413862, 2004.

17. Jutta Gebert, Nicole Radde, and G-W Weber. Modeling gene regulatory networks with piecewise linear dierential equations. European Journal of Operational Research, 181(3):11481165, 2007.

18. Jason N. Bazil, Karl D. Stamm, Xing Li, Raghuram Thiagarajan, Timothy J. Nelson, Aoy TomitaMitchell, and Daniel A. Beard. The inferred cardiogenic gene regulatory network in the mammalian heart. PLOS ONE, 2014 